\title{
Making Better Doctors - Using Mind-Body Medicine Skills as a Self-Care Element in Medical Education at the Charité University Medical School
}

\author{
Benno Brinkhaus $^{\mathrm{a}}$ Claudia Witt ${ }^{\mathrm{a}, \mathrm{b}}$ \\ ${ }^{a}$ Institute for Social Medicine, Epidemiology and Health Economics, Charité University Medical Center Berlin, Germany \\ ${ }^{\mathrm{b}}$ Center for Integrative Medicine, University of Maryland School of Medicine, Baltimore, MD, USA
}

\section{Stress and Its Consequences at Medical School}

The education at a medical school is a time of significant psychological distress for physicians in training [1]. High workloads associated with stress are common to the medical profession and ethical conflicts as well as the exposure to human suffering and death are further unique stressors for medical students. This can lead to physical exhaustion and mental fatigue among students. The inability to cope successfully with the enormous amount of stress may lead to a cascade of consequences at both a personal and professional level. Stress negatively impacts performance, and there is evidence that even empathy declines during medical school [2]. Considering the future doctor shortage, stress in the medical profession is only likely to increase. Taking into account that a good doctor needs to have both medical as well as communicative/psycho-social competencies [3], this prospect of increased stress threatens the quality of future health care and demonstrates the utmost importance of promoting self-care for medical students.

\section{Mind-Body Medicine}

Mind-Body Medicine (MBM) is a good option for promoting selfawareness and self-care to enhance resilience and well-being in medical students. When using an experiential approach to teach MBM skills, students can achieve self-awareness and self-reflection in order to engage in self-care [4]. MBM takes into account the connectedness between the mind and body and its effect on overall health. It is based on two principal notions: i) stress plays a major role in the pathogenesis of disease and ii) relaxation methods and mindfulness in life are beneficial to health. Solid evidence for both assumptions is increasing [5]. As Michalsen [5] points out, it is time to implement MBM more broadly into health care.

\section{Mind-Body Medicine as a Self-Care Element in Medical Schools}

The preventive aspect of MBM characterizes the earlier the better approach for implementing it as self-care element into medical education. The Association of American Medical Colleges (AAMC) in the USA recognized the importance of self-care and has called for medical schools to attend to the health and well-being of medical students as one component of improving the quality of future medical care [6,7]. Medical schools are an ideal environment to encourage students to practice self-care habits in a challenging yet relatively nurturing environment [6]. In the USA, self-care and wellness for students plays an increasing role, as shown by leading examples such as that of the University of Maryland, which has developed a whole wellness and health care center for its students and staff ( $w w w . h e a l t h . u m d . e d u)$. A prime example for a well-implemented, experiential self-awareness program that is based on developing MBM skills is the course at the Georgetown University (Washington, USA), which has been running for more than 10 years [4].

\section{The Georgetown University Mind-Body Medicine Skills Course}

The Mind-Body Medicine Skills (MBMS) course from Georgetown University School of Medicine was originally developed at the Center for Mind-Body Medicine in Washington, DC. This program was one of the education project grants funded by the National Institutes of Health National Center for Complementary and Alternative Medicine (NCCAM) which aimed to incorporate knowledge about CAM into the training of health professionals [8]. The aim of

\section{KARGER \\ Fax +497614520714 \\ Information@Karger.de}

www.karger.com (c) 2012 S. Karger GmbH, Freiburg

$1661-4119 / 12 / 0191-0004 \$ 38.00 / 0$

Accessible online at:

www.karger.com/fok
Prof. Dr. Benno Brinkhaus

Institute for Social Medicine, Epidemiology and Health Economics

Charité University Medical Center Berlin

10098 Berlin, Germany

Te. +49 30450 529-002, Fax -90

benno.brinkhaus@charite.de 
this course is to strengthen the students' capacity for selfawareness and self-care by teaching techniques grounded in this approach. Self-awareness is defined as students' understanding of how their personal histories and current personal lives as well as their values, attitudes, and biases affect their care of patients so that they can use their emotional responses in patient care for their own and their patients' benefit [4]. Target groups for this course at the Georgetown University are medical students, graduate students, and faculty members. The formal implementation is quite simple: A group of $10 \mathrm{stu}-$ dents meet 11 times, preferably over 11 consecutive weeks for $2 \mathrm{~h}$ with two faculty members who chair the sessions in a quiet and peaceful setting. Each session is divided into different parts beginning and ending with short meditation phases. After the initial meditation, students in the first half of the course are encouraged to share personal developments and experiences prompted by their interaction with the course content. In addition, all participants, including the chairs, are invited to address important aspects of their daily life. In the second part of the course, participants learn about the background and practice the methods of the most important MBM approaches including meditation, autogenic training, biofeedback, guided imagery, eating meditation, journal writing, art and its reflection, and different forms of movement (dancing and walking meditation). After practicing these MBM methods, the experiences are discussed and reflected upon by going round all of the course participants. An important precondition for this course is that all members of the group agree to confidentiality, trust, integrity, and honesty. By experiencing and integrating these qualities into their lives, students will have the awareness and the capability to bring forth these healing qualities when interacting with patients and colleagues in years to come [8].

More than 300 medical students and more than 60 faculty members have already participated in such courses at the Georgetown University. The courses have been evaluated regularly, and the first results indicate benefits in self-awareness, empathy, and mindfulness and showed decreases in students' perceived stress [4, 9]. In addition, for the first time physiological benefits of this program could be demonstrated. MBM course participants maintained their hormonal balance within the normal range throughout the academic semester while the control group showed significantly increased levels, probably exacerbated by end of semester exam stress [10].

After 10 years of experience with this Georgetown course model, the course leaders decided to offer regular train-thetrainer courses at the Institute of Integrative Health [11] to pass these courses on to more universities. The purpose of this program is to provide faculty members at health professional schools with the necessary training, tools, materials, and strategic thinking to enable them to implement MBM skills to groups at their institutions.

\section{Mind-Body Medicine Courses at the Charité University Medical School in Berlin}

We decided in August 2010 to offer this course as a self-care tool for medical students at the Charité Medical School in Germany. Both authors were trained by Adi Haramati and Nancy Harazduk at the first international train-the-trainer course. Together with deans and professors from institutions in the USA, in the UK, and in the Netherlands, we were introduced to the content and structure of this course in an experiential way. Having both had experience in MBM, this course showed us a way in which these skills could be taught for prevention and to strengthen resilience in a group of medical students exposed to stress. We started the first course at the Charité in October 2010 using the Georgetown concept, having translated the material into German. We were impressed by the results, which went beyond our expectations. The concept worked for both the students and for us as teachers and had a mayor impact at both the professional and the personal level. Important aspects were more awareness for self-care, relaxation, and harmonization of lifestyle as well as positive changes in professional relationships. Based on these experiences and triggered by the constraints of formal teaching at the Charité, we developed, under the supervision of Nancy Haradzuk and Adi Haramati, two further formats for courses of shorter duration for a greater number of participants. The overall experience was again very positive; however, we realized that the original Georgetown format with a smaller group size over a longer time period allowed for greater intensity. Apart from small cultural differences that had to be adapted for those with German cultural heritage (e.g. deleting wording about love), we found that this MBM program from the USA could easily be used at a German medical school. We are now running the 4th facultative course and will continue to develop a broader program.

\section{Conclusion}

From our perspective, this MBMS program is a fundamental and important tool in medical education and one step toward creating better doctors in the future. Therefore, there is a need to find space in the German medical curriculum to integrate programs like this. Currently the Charité is developing one of the most innovative curricula for training medical students ('Modellstudiengang') in Germany, and although selfcare is said to play an important role in a modern curriculum, it is difficult to find the right slot within the set framework. We are fully aware that this program, with its preconditions, cannot be mandatory for all students and have to find an adequate place in a new curriculum. 


\section{Recommendations}

- Facilitating stress resilience in future physicians should be an important part of the education program in medical schools.

- The MBM course from the Georgetown University offers a well-developed, evaluated program, which can easily be implemented and taught on a facultative basis.

- Education and training of faculty members is an important precondition for the implementation of such courses in a broader setting.

\section{Acknowledgement}

This editorial is dedicated to Nancy Harazduk and Adi Haramati, who developed the Georgetown program and who trained and deeply inspired us.

\section{References}

1 Dyrbye LN, Thomas MR, Shanafelt TD: Systematic review of depression, anxiety, and other indicators of psychological distress among U.S. and Canadian medical students. Acad Med 2006;81: 354-373.

2 Neumann M, Edelhauser F, Tauschel D, Fischer MR, Wirtz M, Woopen C, Haramati A, Scheffer C: Empathy decline and its reasons: a systematic review of studies with medical students and residents. Acad Med 2011;86:996-1009.

3 Witt CM: Der gute Arzt aus interdisziplinärer Sicht. Ergebnisse einer Expertenkonferenz.. Die Arzt-Patienten-Beziehung in der modernen Medizin. Göttingen, Vandenhoeck \& Ruprecht, 2010, pp 64-68.
4 Saunders PA, Tractenberg RE, Chaterji R, Amri H, Harazduk N, Gordon JS, Lumpkin M, Haramati A: Promoting self-awareness and reflection through an experiential mind-body skills course for first year medical students. Med Teach 2007; 29:778-784.

5 Michalsen A: Stressed patients, stressed physicians and the need for mind-body medicine. Forsch Komplementmed 2010;17:237-239.

6 Thomas SE, Haney MK, Pelic CM, Shaw D, Wong JG: Developing a program to promote stress resilience and self-care in first-year medical students. Can Med Educ J 2011;2:e32-e36.

7 Association of American Medical Colleges: Report of the Ad Hoc Committee of Deans; Educating Doctors to Provide High Quality Medical Care: A Vision for Medical Education in the United States. Washington, DC, 2004.
8 Elder W, Rakel D, Heitkemper M, Hustedde C, Harazduk N, Gerik S, Haramati A: Using complementary and alternative medicine curricular elements to foster medical student self-awareness. Acad Med 2007;82:951-955.

9 Wong G, Shah K., Harazduk N, Tractenberg RE, Haramati A: Impact of mind-body skills groups on medical students: quantitative analysis of perceptions of stress and mindful awareness. Altern Ther Health Med 2006;12:68.

10 Maclaughlin BW, Wang D, Noone AM, Liu N, Harazduk N, Lumpkin M, Haramati A, Saunders $\mathrm{P}$, Dutton M, Amri H: Stress biomarkers in medical students participating in a mind body medicine skills program. Evid Based Complement Alternat Med 2011;2011:950461.

11 The Institute of Integrative Health. http//tiih.org/ training-retreats. 